\title{
Temas de Revisión
}

\section{El virus de las "noticias falsas" en la pandemia del COVID-19}

\author{
"Fakes news" viruses in the COVID-19 pandemic
}

Gunther Naldo Balarezo-López

"La mejor acción online, logra un efecto offline" (Anónimo). "Demasiadas noticias negativas... también enferman" (Anónimo).

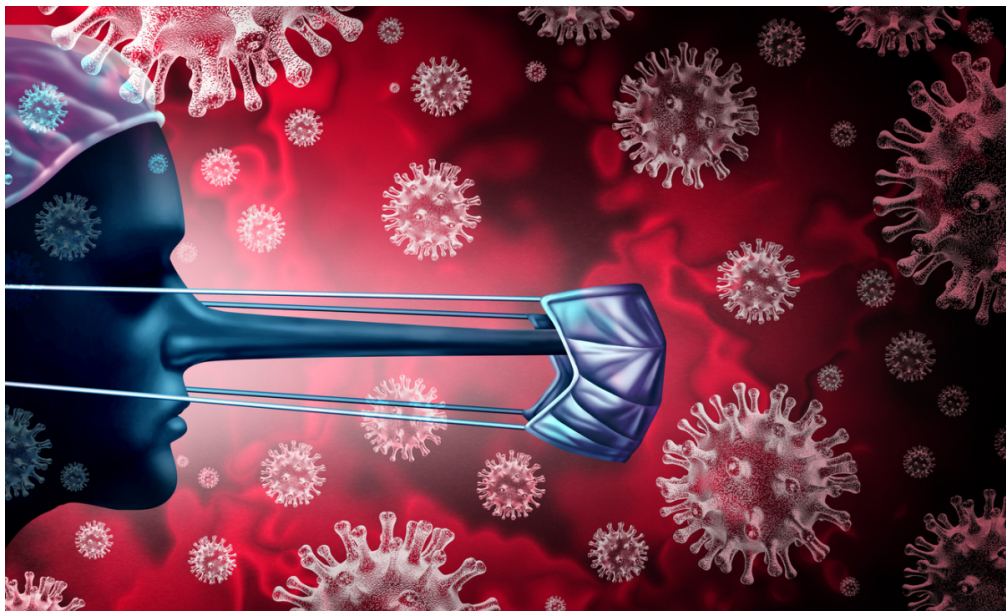

\section{Resumen}

EI COVID-19 no solo es un virus contagioso, también es un virus de noticias falsas que incrementa la angustia, ansiedad y el estrés. Para ello, se hizo una revisión de la literatura, resumiendo los puntos más relevantes con el objetivo de describir aspectos relacionados a la desinformación, la infodemia y las teorías de la conspiración que han estado circulando a través de los medios de comunicación y las redes sociales durante el año 2020 . Se encontró que las noticias falsas se propagan con mayor rapidez que el virus en sí, principalmente por intereses personales, colectivos, económicos y políticos. En tal sentido, se recomienda que la mejor forma de combatir las noticias falsas, es no difundir mensajes sin antes haber verificado la información en fuentes oficiales y autorizadas.

Palabras clave: Virus, noticias, pandemia, COVID-19(DeCS).

\section{Abstract}

COVID-19 is not only a contagious virus, it is also surrounded bay fake news which could lead individuals to experience anxiety, anguish, and even stress. Therefore, literature has been revised including of the most relevant points with the objective of describing aspects relating to the infodemic and false conspiracy theories that have been circulating through the media and social networks. during the year 2020. It was found that the fake news was propagating quicker than the virus itself, primarily due to personal, collective, economic and political interests. Nonetheless, it is recommended that the best way to fight fake news is not to spread messages before having verified the information in official and authorized sources.

Keywords: Viruses, news, pandemic, COVID-19(DeCS).

${ }^{1}$ Docente Escuela de Medicina, Universidad Peruana de Ciencias Aplicadas (Lima-Perú) y Maestría de Salud Pública, Universidad Ricardo Palma (Lima-Perú).ORCID: 0000-0002-6159-8769. 


\section{Introducción}

La segunda década del siglo XXI se caracteriza por los cambios en la diseminación de la información y del conocimiento, a través del uso de las tecnologías y el desarrollo de sistemas masivos de comunicación ${ }^{(1)}$. En este sentido, en el lenguaje de internet, el término 'viral' se utiliza para referirse a lo que se propaga por la red no solo por su velocidad sino también por el daño que puede causar. En la época del COVID19, las redes sociales han sido los medios perfectos para viralizar noticias falsas o 'fake news', y entre ellas las teorías conspirativas $^{(2)}$.

Las 'fake news' es un método de información distorsionada, dudosa, manipulada y malintencionada en los medios de comunicación y en las redes sociales para disfrazar mentiras como si fueran verdaderas para conseguir el máximo impacto. La desinformación es un instrumento de poder, a través del cual es posible viralizar el miedo y el desconcierto y sembrar el pánico social ${ }^{(3-6)}$. Para el filósofo alemán Peter Sloterdjik, los medios son "portadores de infecciones" y la información es un cruce de "emociones, envenenamientos y destrucciones del juicio público"(7).

Un artículo publicado en MIT Technology Review el 12 de febrero de 2020, indica que el COVID-19 se considera la primera pandemia global de las redes sociales, ocasionando una serie de desafíos en relación con la comunicación debido al incremento en la difusión de información falsa mediante de medios digitales, páginas web y mensajería instantánea como WhatsApp ${ }^{(8,9)}$.

\section{Noticias falsas}

Noticias falsas o 'fake news' es una expresión para referirse a la desinformación. El Collins Dictionary las define como "información falsa, a menudo sensacionalista, difundida bajo el disfraz de noticia"(10). El Oxford English Dictionary en el año en 2017, elige el término 'fake news' como la palabra del año y la define como "noticias que transmiten o incorporan información falsa, fabricada o deliberadamente engañosa, o que se caracterizan o acusan de hacerlo" y sitúa el inicio de este término las elecciones presidenciales norteamericanas del $2016^{(11-13)}$. Asimismo, el Cambridge Dictionary define 'fake news' como "historias falsas que aparentan ser noticias, difundidas en internet $u$ otros medios que suelen ser creadas para influir en el punto de vista político o como una broma" (14).

Otra definición es de la Comisión Europea, la cual indica "falso, inexacto o engañoso [...] diseñado, presentado y promovido intencionalmente para causar daño público o beneficios particulares"; indica que es "para engañar o alterar la percepción de forma intencional de grandes grupos de personas o sociedades e influir en su comportamiento (político, económico, ideológico....)"(15,16).

Para David Lazer, distinguido profesor de ciencias políticas y ciencias de la computación y la información en Northeastern University (EEUU), define las ciencias de los 'fake news' como "aquella información fabricada que imita el contenido de los medios de comunicación en la forma, pero no en el proceso o la intención de la organización"; es decir, son piezas de información que procuran lucir reales, tanto por la forma (imitan a aquellas producidas por medios informativos) como por los canales (se publican es espacios que remedan los formatos periodísticos $)^{(17)}$.

Entre las diferentes estrategias y formas utilizadas para crear noticias falsas, las más comunes son: contenido completamente falso, falso contexto, contenido engañoso o manipulado, suplantación, imitación y sátira/parodia ${ }^{(18)}$.

Asimismo, algunos autores distinguen los conceptos de misinformation (información inexacta, errónea y engañosa que se difunde sin intenciones maliciosas) y disinformation (información falsa, inexacta, engañosa, para confundir o manipular, generalmente con fines políticos y/o económicos). La desinformación tiene consecuencias significativas para las personas, los gobiernos y las empresas, al influir en sus acciones y decisiones ${ }^{(1,19-22)}$.

Para la Organización Panamericana de la Salud (OPS), la desinformación es la información falsa o incorrecta con el propósito deliberado de engañar. En el contexto de la pandemia actual, puede afectar en gran medida todos los aspectos de la vida, en particular la salud mental, dado que las búsquedas sobre el COVID-19 se han incrementado debido a la facilidad de publicación en la internet $t^{(1,20,23)}$. En este sentido, The Vaccine Confidence Project, entre el 1ro. de enero del año 2020 y hasta mediados de marzo, detectó más de 240 millones de mensajes relacionados con la pandemia de COVID-19 compartidos mundialmente a través de las redes sociales y otros medios de comunicación, con un promedio de 3,08 millones de mensajes $\operatorname{diarios}^{(24)}$.

El COVID-19 ha originado la mayor cantidad de rumores y de desinformación conocida; se han subido 361.000 .000 videos en YouTube en las categorías de "COVID19 " y "COVID 19", y desde que comenzó la pandemia se han publicado cerca de 19.200 artículos en Google Académico. En el mes de marzo, unos 550 millones de tuits incluyeron los términos coronavirus, corona virus, COVID19, COVID-19 o pandemia ${ }^{(23)}$. Asimismo, a mediados de abril, la base de datos CoronaVirusFact Alliance, impulsada por el Poynter Institute y la International Fact-Checking Network, registraba 3.800 engaños relacionados con el coronavirus circulando por todo el mundo: https://www.poynter.org/coronavirusfactsalliance ${ }^{(24)}$.

En este sentido, la Organización Mundial de la Salud (OMS) recomienda "Minimice el tiempo que dedica a mirar, leer o escuchar noticias que le causen ansiedad o angustia. Busque información únicamente de fuentes confiables. Infórmese sobre lo que en realidad está sucediendo, no escuche los rumores y la información errónea. Recopile información del sitio web de la OMS y de la OPS y de las plataformas de las autoridades nacionales y locales de salud, a fin de ayudarle a distinguir los hechos de los rumores..."(25). Además, la Comisión Europea recomienda el no compartir información que no haya sido verificada y que proceda de fuentes dudosas $^{(26)}$.

Muchas historias falsas o engañosas se inventan y difunden sin comprobar su veracidad ni calidad. Gran parte de esta desinformación se basa en teorías de la conspiración. Sobre el coronavirus, ha circulado información inexacta y falsa 
sobre el origen del virus, la causa, el tratamiento, el mecanismo de propagación, población infectada e inmunidad frente a la enfermedad, implicaciones económicas, etc. La desinformación puede difundirse y asimilarse muy rápidamente, dando lugar a cambios de comportamiento que pueden llevar a que las personas tomen decisiones equivocadas y mayores riesgos. Todo esto hace que la pandemia sea mucho más grave, perjudique a más personas y ponga en peligro el alcance y la sostenibilidad del sistema de $\operatorname{salud}^{(1,23)}$. La difusión de información falsa puede tener consecuencias muy graves, ya que conduce al miedo, a una menor respuesta a las advertencias sobre el distanciamiento social o la higiene, a la desconfianza en la medicina y a hacer uso de prescripciones inapropiadas, ineficaces o perjudiciales ${ }^{(27)}$.

De otro lado, el contexto tecnológico favorece la difusión dado el aumento de personas con disponibilidad de internet y el acceso a teléfonos celulares, la disponibilidad de aplicaciones para la edición y la publicación de imágenes, textos y audios y las plataformas de redes sociales que permiten (como el WhatsApp), la circulación de información en tiempo real y con menos posibilidades de ser desmentidas ${ }^{(28)}$. Asimismo, en la vida virtual más que en la vida real, las personas se rodean de gente que piensa parecido a ellos, y así seleccionan, comparten y hacen "viral" información que refuerza sus propios prejuicios e ideas preconcebidas. La carga emocional de la "noticia" siempre es mayor que el uso de la razón en el momento de compartir mensajes del WhatsApp, tuits o videos ${ }^{(29)}$

Asimismo, el director general de la OMS, señala que las personas deben tener acceso a información precisa para protegerse a sí mismas y a los demás; se debe combatir la propagación de rumores y la desinformación porque las noticias falsas se propagan más rápido y fácilmente que el virus. La infodemia (la expansión de falsas informaciones y noticias engañosas) obstaculiza las medidas de contención del brote, difundiendo pánico y confusión de forma innecesaria y generando división en un momento en el que se necesita ser solidarios. La OMS no solo está luchando contra el virus también lucha contra los provocadores y los teóricos de la conspiración que promueven la desinformación. No solo se está luchando contra una epidemia; también se está luchando contra una infodemia ${ }^{(1,21,27,30,31)}$.

Pero muchas veces estos esfuerzos se dificultan por una pandemia de desinformación, por su relación con las ideas y creencias acerca del origen del virus, formas de contagio, síntomas, cómo evitar el contagio, diagnóstico, formas de tratamiento, medicamentos para combatir la enfermedad y aislamiento social ${ }^{(6,18,20,32)}$. Además, uno de los problemas con los que se encuentra la lucha contra las noticias falsas es que todavía no hay pruebas definitivas disponibles para refutar algunos rumores virales, por lo que estos persisten ${ }^{(24)}$.

Para ello, cuando el COVID-19 es declarado una emergencia de salud pública a nivel internacional, el equipo de comunicación de riesgos de la OMS lanza una nueva plataforma de información llamada Red de Información para Epidemias (EPI-WIN), que tiene como objetivo garantizar la veracidad de la información oficial comunicada al público a través del intercambio con profesionales que emiten recomendaciones y a su vez reciben información sobre el COVID-19 ${ }^{(33)}$.

\section{Infodemia}

En el año 2002, el investigador canadiense Gunther Eysenbach acuña el término de infodemiología a la epidemiología de la información, considerándola como una disciplina y metodología de investigación interdisciplinaria que estudia los determinantes y la distribución de información y desinformación en salud; esto es útil para guiar la obtención de información de calidad sobre salud en internet, tanto para los profesionales de la salud como para los pacientes ${ }^{(34,35)}$.

En el 2003, el término infodemia, que es un neologismo de 'fake news', se utiliza para describir situaciones donde un conjunto de hechos mezclados con miedo, especulación y rumores, son distribuidos a una audiencia mundial gracias al uso de las tecnologías de la información, con posibilidades de impactar de forma desproporcionada en la seguridad, economía y política de los países ${ }^{(18,36,37)}$. En el contexto del COVID-19, se utiliza para designar los peligros del fenómeno de la desinformación durante la gestión de la pandemia, debido a que las informaciones falsas podrían acelerar la expansión de la enfermedad influenciando en la respuesta y el comportamiento social $^{(38,39)}$.

La 'infodemia' se refiere al juego de palabras entre información y pandemia, y según el Instituto Reuters de la Universidad de Oxford (Reino Unido), los políticos, las celebridades y los 'influencers' han sido los responsables de producir o propagar el $20 \%$ de la información falsa sobre el coronavirus en las redes sociales. Esta infodemia trata de la sobreexposición informativa a la que se ha estado expuesto en un ambiente de preocupación, estrés, ansiedad y angustia durante la pandemia ${ }^{(2,40,41)}$

En el año 2018, la OMS en su libro Manejo de Epidemias: Datos Clave Sobre las Principales Enfermedades Mortales define la infodemia como la rápida difusión de información de todo tipo, incluidos rumores, chismes e información poco confiable que se propaga de manera instantánea e internacional a través del uso de los teléfonos móviles, las redes sociales, el internet y otras tecnologías de la comunicación ${ }^{(35)}$.

La OMS utiliza el término infodemia (infodemic) desde mediados de febrero del 2020 para referirse a la sobreabundancia de información falsa y a su rápida propagación entre las personas y medios en relación al COVID-19. En una publicación de la revista The Lancet se indica que "El término infodemia se refiere a un gran aumento del volumen de información relacionada con un tema particular, que puede volverse exponencial en un período corto debido a un incidente concreto en la pandemia, apareciendo en escena la desinformación y los rumores, junto con la manipulación de la información con intenciones dudosas. En la era de la información, este fenómeno se amplifica mediante las redes sociales, propagándose más lejos y más rápido, como un virus". En este caso, el mayor acceso en el mundo a los teléfonos celulares con conexión a internet y a las redes sociales ha dado lugar a la producción exponencial de información y de las modalidades para obtenerla, creando una epidemia de la información $^{(1,16,23,27,42)}$. A los altos niveles de estrés que provoca la amenaza el virus, se suma la ansiedad que provocaba el confinamiento social en los hogares. En este contexto se 
aceleró el consumo de las Tecnologías de la Información y Comunicación (TIC) y con ello, la sobreexposición a información sobre el tema, agregando así al fenómeno de la pandemia, el de la 'infodemia, ${ }^{\text {(25). }}$.

La infodemia se extiende de forma acelerada, influenciando en el comportamiento de la población e impidiendo su adherencia a las medidas sanitarias de prevención. El factor amplificador de la infodemia es principalmente el acceso a las redes sociales, cuyo uso se incrementó durante la pandemia a nivel global. La infodemia ha puesto en riesgo la salud humana debido a la comunicación distorsionada de hechos con evidencia científica débil y la difusión de teorías pseudocientíficas $^{(44)}$. Para el filósofo Pedro Cornejo, el problema es que actualmente se produce un fenómeno adicional e inédito: la sincronización de la pandemia viral con la informativa ${ }^{(7)}$.

Para la OPS y la OMS, la infodemia puede empeorar la pandemia debido $\mathrm{a}^{(23)}$ :

-Dificulta que las personas, los encargados de tomar las decisiones y el personal de salud encuentren fuentes confiables y orientación fidedigna cuando las necesitan. Entre las fuentes figuran las aplicaciones para teléfonos celulares, las organizaciones científicas, los sitios web, los blogs y las personas influyentes, entre otras.

-Las personas pueden sufrir ansiedad, depresión, agotamiento emocional y sentirse incapaces de satisfacer necesidades importantes.

- Puede afectar los procesos de decisión cuando se esperan respuestas inmediatas, al no dedicar el tiempo suficiente para analizar a fondo los datos científicos.

- No hay ningún control de calidad en lo que se publica y a veces tampoco lo hay en la información que se utiliza para adoptar medidas y tomar decisiones.

- Cualquier persona puede escribir o publicar algo en internet, en especial en las redes sociales.

\section{Teorías de la Conspiración}

Las teorías de la conspiración siempre han existido y durante la pandemia del COVID-19, han surgido nuevas y diversas teorías. Estas teorías suelen diseminarse en períodos de tensión política o en situaciones como guerras, crisis, pandemias, etc. y sirven para sembrar "semillas de desconfianza" o lo que los psicoanalistas llaman "sentimientos persecutorios" ${ }^{\text {(45,46). }}$

En este contexto, el término conspiranoia ha vuelto a tener vigencia; originalmente se refería a una obsesión por las teorías conspirativas cuando estas se consideraban sin fundamento o basadas en datos falsos. El periodista peruano Renato Cisneros se refiere a estas personas como "conspiranoicos". Actualmente, el Diccionario General de la Lengua Española de Vox la define "serán el resultado de la conspiración de grupos de poder o de personas influyentes"(45).
Para la desinformación, la internet y las redes sociales cumplen un rol importante ya que si no existieran no se podría dar la desinformación. Anteriormente, la manipulación y la mentira se limitaban a los periódicos o la televisión que tenían una capacidad de emisión limitada. Actualmente, las plataformas digitales favorecen a que se viralicen determinados contenidos, dado que la información es actualizada constantemente y en tiempo real genera incertidumbre en las personas ${ }^{(5)}$. Asimismo, si bien la infodemia se moviliza a través de las redes sociales y los celulares, gran parte de esta también proviene de los medios de comunicación tradicionales (televisión, radio y prensa escrita); es por ello que los especialistas en salud pública deben colaborar con dichos medios a comprender mejor lo que sucede con el virus ${ }^{(33)}$.

Incluir todas las teorías conspirativas surgidas durante la pandemia del coronavirus, sería una labor casi imposible. Por ello, se ha tomado las que han tenido mayor difusión a través de las redes sociales y diversos medios de comunicación, en especial la prensa escrita. Entre las principales teorías de conspiración se tiene las siguientes ${ }^{(6,24,25,27,35,36,40,42,46,48-69)}$ : MesoAyerdi, \& Mendiguren-Galdospín, 2020; El SARS-CoV-2 ha sido creado en el laboratorio, hipótesis promovida por la bióloga Judy Mikovits quien asegura que existe una agenda detrás del COVID-19 desde su creación en laboratorios de China como arma biológica contra Estados Unidos. Para Donald Trump, el Instituto de Virología de Wuhan (China) fue el origen del coronavirus y por ello califica la pandemia como el "virus de China", debido a que en esta ciudad está el más importante laboratorio de virología de China, en el que se encuentra el banco de virus más importante de toda Asia, donde se preservan más de 1.500 especies virales, entre ellas las más patógenas.

-El virus ha sido creado en un laboratorio de Fort Detrick en Maryland (EEUU) para frenar el desarrollo de la tecnología $5 \mathrm{G}$, o como medida drástica para frenar el crecimiento de la población.

-El grupo Qanon promueve que Bill Gates está detrás de la pandemia, señalándolo como el financista del SARSCov-2. El objetivo de Gates sería alentar la vacunación y deshacerse de un porcentaje de la población mundial (especialmente los pobres y ancianos). Esta idea surgió en marzo de este año cuando en una entrevista Gates dijo que "eventualmente tendremos algunos certificados digitales para mostrar quién se ha recuperado [de COVID-19] o ha sido evaluado, o cuando tengamos una vacuna, quién la ha recibido".

-Las vacunas vienen con nanochips, lo cual involucra a Bill Gates y al magnate George Soros; en las vacunas se pondrían nanochips con el objetivo de "controlar la actividad cerebral". En el Perú, según una encuesta de El ComercioIpsos, el número de personas que no se vacunarían contra el virus porque creen que este tendría un microchip con fines de control y que puede causar otras enfermedades, pasó de $22 \%$ en agosto a $40 \%$ en diciembre. Según el cantante español Miguel Bosé "Si nos quieren vacunar obligatoriamente, sospecho que hay algo dictatorial detrás"; el rapero Kanye West afirma que las vacunas solo servirían para instalarnos microchips vigilantes. Esta vacunación con inteligencia artificial significa Certificado de Identificación de Vacunación con Inteligencia 
Artificial y lleva el número 19 porque se creó en el 2019. Todo un plan secreto para controlar y reducir poblaciones.

-La quinta generación $(5 \mathrm{G})$ de redes inalámbricas de celulares propaga el virus a través de las redes de telefonía celular y la radiación de tales redes suprime el sistema inmunitario contra el virus, lo que convence a muchas personas para que salgan a las calles y prendan fuego a las antenas $5 \mathrm{G}$ en varios países (Australia, Nueva Zelanda, Reino Unido, Irlanda, Finlandia, Suecia, Bélgica, los Países Bajos e Italia). En nuestro país, esta teoría lleva a que los comuneros de Acobamba (Huancavelica) retuvieran a trabajadores de telecomunicaciones por la creencia de que instalaban antenas $5 \mathrm{G}$. Estos ataques conspiratorios son promovidos por el movimiento activista anti-5G liderados por los grupos Stop 5G que hay alrededor del mundo. Según la OMS, los virus no pueden viajar a través de ondas de radio ni redes de telefonía móvil "Una onda electromagnética no puede trasladar un elemento biológico, como un virus".

-El coronavirus es una bacteria, y como tal, se puede tratar con aspirinas y antibióticos.

-El virus lo esparcen desde el aire, afirmación hecha por el congresista de Acción Popular Orlando Arapa desde un programa radial en Puno: "Nos han dicho que probablemente están circulando avionetas, drones esparciendo el coronavirus".

-Las mascarillas no sirven a ningún propósito sanitario, son contaminantes y su uso prolongado provoca intoxicación por dióxido de carbono provocando hipoxia y activa el propio virus.

-Donald Trump señala que la OMS y China confabularon para ocultar evidencia de la pandemia en su etapa inicial, dando credibilidad a la información brindada por el país asiático, dado que se impidió a investigadores constatar in situ el estado de la pandemia. La OMS se limitó a divulgar información que China le brindó.

-El canciller brasileño Ernesto Araújo acuña el término 'comunavirus' para referirse a que el comunismo usa la cuarentena para conspirar contra el capitalismo.

-Según China, el virus es una creación estadounidense, porque lo llevaron soldados estadounidenses durante su participación en las olimpiadas militares que se realizaron en el 2019 en Wuhan (China).

-Donald Trump en una entrevista que le concede a 'Fox News' afirma que los niños son 'casi completamente' inmunes al coronavirus. Twiter y Facebook le dieron de baja a la publicación, alertando que incluía información falsa y potencialmente perjudicial.

-La reina del pop Madonna, fue censurada en Instagram luego de compatir con 15 millones de seguidores un video en el que asegura que la vacuna del COVID-19 ya había sido encontrada, pero que era mantenida oculta para beneficiar a los ricos del mundo.

-Carlos Villagrán (Quico en la serie 'El Chavo del Ocho') dijo en un programa de televisión que "en el mundo no existe el COVID-19", sino que es un mecanismo para espantarnos y mantenernos encerrados. Lo que existe es un plan de dominación global que usa el miedo para lograr sus objetivos.

-Arturo Fernández, el alcalde de Moche (al norte del Perú) no solo se declara en rebeldía y afirma que no acatará la cuarentena, sino que le envía una carta al presidente Martín Vizcarra firmada con su sangre; también asegura que tomar dióxido de cloro ayuda a mejorar la potencia sexual: "Me dicen que los pacientes que tenían antes problemas de erección y que tenían que tomar una pastilla, ahora ya no les piden eso. Un porcentaje que tomó dióxido de cloro, su potencia sexual se ha recuperado". Además, dice que el compuesto químico le brinda más energía y mayor vitalidad.

-Se busca voluntarios para participar en ensayos clínicos para una vacuna en países como el Perú, donde "falta control y se toma a la gente como conejillos de indias".

-Los gobiernos y la prensa ocultan que la gente que supuestamente está muriendo, es en realidad parte de una gran simulación funeraria. Los entierros se realizan con túneles. Los falsos fallecidos escapan y vuelven a morir al día siguiente.

- Se especula que la pandemia sería el anuncio de la inminente llegada del apocalipsis.

-Se tiene la idea de que la pandemia es una amenaza exterior, por lo que se pide el cierre de las fronteras, con lo que se vincula la inmigración a la amenaza sanitaria.

-Bañarse con agua caliente previene la infección.

-El virus no puede transmitirse en zonas con climas cálidos y húmedos. El virus no resiste el calor y se muere si está expuesto a temperaturas mayores a 26-27 grados.

- Como medida de prevención, hacer gárgaras con agua tibia y sal o vinagre, elimina el virus.

-El coronavirus se elimina con metanol.

-Donald Trump tuitea que, supuestamente algunos complementos alimenticios y que la hidroxicloroquina y la azitromicina que se utiliza para el tratamiento del paludismo, previenen, tratan o curan las infecciones por coronavirus.

-Se recomienda un alto consumo de vitamina $\mathrm{C}$ y $\mathrm{D}$, debido a su relación con el sistema inmune, a pesar de que no existe evidencia científica de su efectividad en la prevención o recuperación de COVID-19.

-Se propone aplicar inyecciones a base de desinfectantes y el uso de medicamentos como la cloroquina y de hidroxicloroquina justificando que serían tratamientos eficaces.

-Debe consumirse abundantemente bebidas calientes como infusiones, caldos o simplemente agua tibia, porque neutralizan el virus. 
- Tomar agua hervida con ajo ayuda a combatir el virus.

- Evitar tomar agua helada o bebidas con hielo.

-Medios rusos sugieren que el COVID-19 fue creado en un laboratorio en Georgia (Estados Unidos).

-Mediante un tuit el presidente de Venezuela, Nicolás Maduro, dice que el virus es una posible arma biológica dirigida a China, además de recomendar recetas naturales para curar el virus.

-Se denomina el COVID-19 como "virus de los ricos", dado que es un virus que ataca solo a aquellas personas con alto poder adquisitivo que tienen la posibilidad de viajar al exterior, ya que en un principio fueron los turistas quienes transportaban el virus por todo el mundo.

-Se coloca el adjetivo de "bombas de tiempo" a las residencias geriátricas o centros de mayores que sufren intensamente los embates del virus, y ese término es utilizado frecuentemente en los medios de comunicación.

-Contener la respiración por cierto lapso de tiempo, es una prueba para saber si se tiene el COVID-19.

- Beber mucha agua ayudaría a que desaparezca la enfermedad.

-La sopa de murciélago es la causante del virus.

-El presidente venezolano Nicolás Maduro anuncia que los científicos de su país descubren en solo seis meses, la molécula que logra la aniquilación en $100 \%$ del virus que causa el COVID-19, sin ningún tipo de toxicidad sobre las células sanas.

-El presidente brasileño Jair Bolsonaro anuncia que los científicos brasileños logran probar que el antiparasitario nitazoxanida es la medicina que "cambiará para siempre la historia de la pandemia".

- Las vacunas para prevenir el COVID-19 son 'sustancias transgénicas' que esterilizarán a los hombres y modificarán el ADN de quienes la reciban.

-El congresista de Unión por el Perú, Posemoscrowte Chagua, se muestra en contra de la compra y distribución de vacunas para frenar el COVID-19 debido a que estas pueden 'dañar y modificar el ADN' de los peruanos. El 'ADN del pueblo está en juego' y los congresistas que aprueben la vacuna 'serán denunciados'. Asimismo, la congresista de Fuerza Popular Martha Chávez, desconfía de la industria farmacéutica y cree que sufrirán mutaciones genéticas si se aplican las vacunas contra el COVID-19.

- No se puede tener una vacuna segura en tan poco tiempo; casi todas las vacunas que se tienen disponibles han tardado en desarrollarse entre 4 y 30 años. Sin embargo, que las nuevas tecnologías y los avances en biología molecular permiten acortar estos períodos. Según el Dr. Ciro Maguiña, profesor principal de la Universidad Peruana Cayetano
Heredia, "Lo que antes demoraba cuatro años o más, ahora se puede hacer en un año".

-Una mujer dice que Facebook la está censurando y que ella tiene la verdad. Habla de un plan para matar a 5000 millones de personas y destruir al mundo tal cual lo conocemos. Dice que en el Perú se está imponiendo la vacunación contra el COVID-19 con militares en las calles y que cambiarán la genética humana para siempre. El video dura 10 minutos.

-El presidente Martín Vizcarra asegura que “el Perú contará en el primer trimestre del próximo año con una vacuna contra el COVID-19". Asimismo, el canciller Mario López sostiene que "El Perú se encuentra en la primera fila y en los primeros lugares para acceder a la vacuna (...) firmó acuerdos vinculantes con Pfizer y la iniciativa Covax Facuility, mediante los cuales se asegura una cantidad de dosis de vacunas que permitirán atender a más de 11 millones de peruanos en primer trimestre del 2021".

-El presidente Martín Vizcarra, menciona que cuando ya estaban a punto de cerrar las negociaciones con los laboratorios para adquirir la vacuna contra el COVID-19, el Congreso lo vaca y se pierde todo lo avanzado.

-El presidente Martín Vizcarra asegura que ya se firmó un contrato con el laboratorio Covax Facility por más de 11 millones de vacunas, las que serán entregadas en el año 2021. Estas llegarían a más tardar para el bicentenario y todos los peruanos estarían vacunados.

En el 2016, el físico, escritor y divulgador científico David Robert Grimes de la Universidad de Oxford, en vez de intentar desestimar las teorías de la conspiración, toma el camino contrario: calcular cómo podrían ser posibles. De esa forma, crea una ecuación que expresa la probabilidad de que una conspiración sea deliberadamente descubierta por un denunciante o inadvertidamente revelada por un torpe o un 'bocazas'. Entre los factores a tener en cuenta están el número de conspiradores, la cantidad de tiempo, e incluso la posibilidad de que mueran los conspiradores, ya sea de vejez o por otros medios $^{(70)}$.

Las teorías de la conspiración no necesitan estar sustentadas en hechos reales para volverse viral, sino que necesitan de personas; basta que alguien lo crea y lo difunda ${ }^{(50}$.

\section{Discusión}

La desinformación es una enfermedad altamente contagiosa y su transmisión se realiza entre individuos que tienen como base la carencia de conocimientos, habilidades y actitudes para el uso e interpretación adecuada de la información ${ }^{(1)}$.

Esta pandemia ha modificado el sentido de la normalidad, ha desatado el miedo y ha generado un terreno fértil para la propagación de ideas conspirativas o soluciones mágicas. La mentira está cada vez más legitimada y hasta se ha vuelto un entretenimiento $^{(46)}$. Para el infectólogo Augusto Tarazona, presidente de la Comisión de Salud Pública del Colegio Médico del Perú, "el temor se genera por el desconocimiento"(65). 
Dado que la desinformación se difunde por intereses particulares o simplemente ignorancia mediante las redes sociales, algunas plataformas (Facebook, Twitter e Instagram) han habilitado una opción para que cada vez que un usuario busca un 'hashtag' en particular, sea derivado a información proporcionada por fuentes autorizadas como la OMS. En otros casos, se envía advertencias a los infractores o se elimina sus cuentas $^{(2,20,71,72)}$. En el caso del WhatsApp (una de las principales plataformas usadas para compartir noticias falsas), limita a cinco como máximo las veces que puede compartirse un mensaje $\mathrm{e}^{(71,73)}$. You Tube elimina el contenido de las informaciones que contradigan a las autoridades sanitarias, tales como los Institutos Nacionales de Salud del Reino Unido o la OMS; mientras que Tik Tok incluye un signo que dirige a información permanente sobre el COVID-19 y los videos que sean sobre el tema aparecen con una placa informativa ${ }^{(71)}$.

Para Francesco Rocca, de la Federación Internacional de Sociedades de la Cruz Roja y de la Media Luna, "Para vencer al COVID-19 es necesario vencer la pandemia paralela de desconfianza, que ha obstaculizado constantemente nuestra respuesta colectiva a esta enfermedad y que podría mermar nuestra capacidad compartida de vacunarnos contra ella". De otro lado, para Markus Rimmele, director del Centro Alemán de Información para Latinoamérica del Ministerio Federal de Relaciones Exteriores de Alemania, "Debemos buscar buena información, sobre todo en tiempos de pandemia. Hay que aprender a reconocer la información confiable. Compartir informaciones falsas hoy puede tener un impacto negativo muy serio. Las 'fake news' en pandemia pueden llevarnos a más infecciones y hasta a más muertes"(52).

Ante esta situación que implica la salud de la población, se hace necesario basar las decisiones en evidencias científicas. La desinformación es una enfermedad que prolifera porque encuentra sectores de la población que no están informados, y por lo tanto se necesita un trabajo coordinado para enfrentarlo entre los gobiernos, las organizaciones líderes a nivel mundial, las instituciones académicas, los sistemas de información y los medios de comunicación ${ }^{(64)}$. A ello se suma que, según la infectóloga Theresa Ochoa del Instituto de Medicina Tropical Alexander Von Humboldt de la Universidad Peruana Cayetano Heredia, "la gente está más relajada en el control y ahí es donde los grupos de desinformación aprovechan para difundir mentiras" ${ }^{(65)}$.

La implementación de políticas de información que insten a las organizaciones e instituciones científicas, educativas y culturales a trabajar de forma coordinada en estrategias desde edades tempranas contribuirá a formar individuos preparados para insertarse en la sociedad de la información y el conocimiento, utilizando las herramientas y tecnologías de la información con responsabilidad. Tener ciudadanos informados implica garantizar el acceso equitativo a la información, el fomento de su autonomía y el desarrollo de su capacidad crítica $^{(1)}$

\section{Conclusiones}

Se sugiere que para contrarrestar la infodemia se debe emitir y reiterar mensajes claros, libres de jerga y prácticos para que las personas los puedan asumir. Asimismo, la profesora Heidi Tworek (profesora de Historia en Columbia Británica Canadá), propone seguir unos pasos prácticos que $\operatorname{son}^{(74)}$ :

- No sobrecargar a las personas con información, usar viñetas cortas y compartibles.

-Incluir imágenes y fotos con texto que ayuden a recordar o videos con audio y subtítulos.

-Incluir infografías como diagramas de flujo, líneas de tiempo y diagramas de Venn.

- Usar videos educativos e instructivos divertidos, de acuerdo con el público objetivo.

Combatir la infodemia debe ser un esfuerzo conjunto de los gobernantes, la comunidad científica, la comunidad médica y los medios de comunicación. Los consejos para la población es preguntarse siempre quién envío la información y cuál es la fuente; si se desconoce la fuente de la información es mejor no compartirla; reportar los rumores pseudocientíficos; confiar en los científicos y en las organizaciones que velan por la salud como la OMS; no confiar en cadenas de WhatsApp; y dirigirse siempre a las fuentes oficiales ${ }^{(36)}$. Las acciones también dependerán de factores demográficos, sociales, culturales y conductuales de la población, además de la participación consciente, solidaria y desinteresada de las autoridades nacionales, regionales, locales, así como de los medios de difusión de noticias en red y por medios convencionales ${ }^{(35)}$.

Finalmente, desde el año 2018 se utiliza la técnica del 'deepfake' que se vale del reconocimiento facial y la inteligencia artificial. En ese mismo año, la ONG Center for a New American Security (CNAS) publica un estudio en el que se señala que hacia el 2023, el 'deepfake' iba a ser capaz de engañar a una audiencia no entrenada con la finalidad de "difundir contenido falso o engañoso". En tal sentido, los expertos advierten sobre los peligros de esta tecnología que puede llevar las 'fake news' a un nuevo nivel de desinformación general $^{(75)}$.

Referencias bibliográficas

1.AIfonso-Sánchez IR, Fernández-Váldez MM. Comportamiento informacional, infodemia y desinformación durante la pandemia de COVID-19. Disponible en: http://www.revistaccuba.cu/index.php/ revacc/article/view/882

2. Fangacio JC. Otro virus anda suelto. Diario El Comercio, Lima 2020, setiembre 12. Tema del Día, Sección El Dominical:p.2.

3.Zhou L, Zhang D. An ontology-supported misinformation model: toward a digital misinformation library. IEEE Transactions on Systems, Man, and Cybernetics-Part A 2007;37(5): 804-813.

4.Giusti M. Preocupación a la manipulación deliberada de los hechos. Diario El Comercio, Lima: 2020, setiembre 26. Sección ElDominical:p.2.

5.Lira-Delcore A. En el uso de la desinformación, los extremos se 
tocan. Diario El Comercio, Lima: 2020, setiembre 6. Entrevista del Domingo, Sección El Dominical: pp. 8-9.

6. Pinheiro-Cantuário VA. "Isso é verdade?" - a "infodemia" da pandemia: considerações sobre a desinformação no combate à COVID-19. Investigação Filosófica 2020;11(2):175-188.

7. Cornejo P. Pandemia y política. Diario El Comercio, Lima: 2020, noviembre 15. Filosofía 3.0, Sección El Dominical, p. 15.

8. Elías C, Catalan-Matamoros D. Coronavirus in Spain: fear of 'official' fake news boosts WhatsApp and alternative sources. Media and Communication 2020;8(2):462. doi.org/10.17645/ mac.v8i2.3217

9. Hao K, Basu, T. The coronavirus is the first true social-media "infodemic". Disponible en: https://www.technologyreview. $\mathrm{com} / 2020 / 02 / 12 / 844851 /$ the-coronavirus-is-the-first-truesocial-media-infodemic/

10.Rodríguez-Ferrándiz R. Posverdad y fake news en comunicación política: breve genealogía. El Profesional de la Información 2019;28(3). https://doi:org/10.3145/epi.2019. may. 14

11.Oxford Dictionary. Fake news. Disponible en: https://oed.com/view/Entry/67776\#eid1264306660

12. Pérez-Dasilva JA, Meso-Ayerdi K, Mendiguren-Galdospín T. Fake news y coronavirus: detección de los principales actores y tendencias a través del análisis de las conversaciones en Twitter. El Profesional de la Información 2020;29(3), e290308. https://doi.org/10.3145/epi.2020.may.08

13. Torrealba M, Viloria Y. De la verdad y de la ruta propuestapara la verificación por el OVFN. La Mentira en la Censura. Los Fake News en Venezuela, M. Torrealba, L. Hernández \& A. Cañizález (Coordinadores), Primera Edición, Universidad Católica Andrés Bello, Caracas, 2020:125.

14. Niño-Gamboa AJ. Fake News: una nueva oportunidad para reafirmar la libertad de expresión. La Mentira en la Censura. Los Fake News en Venezuela, M. Torrealba, L. Hernández \& A Cañizález (Coordinadores), Primera Edición, Universidad Católica Andrés Bello, Caracas, 2020: 34.

15. European Commission. A multidimensional approach to disinformation. Report of the independent high level group on fake news and online disinformation. Directorate-General for Communication Networks, Content and Technology [Internet], Union Europea. Disponible en: http://bit.ly/2Ponxc1

16. Del Fresno-García M. Desórdenes informativos: sobreexpuestos e infrainformados en la era de la posverdad. El Profesional de la Información 2019;28(3), e280302. https://doi.org/10.3145/epi. 2019.may.02

17. Garrido-Koechlin, JJ. De los '¿fake news' a los medios fake. Diario El Comercio, Lima: 2020, noviembre 29. Opinión: p.31.

18. García-Marín D. Infodemia global. Desórdenes informativos, narrativas fake y fact-checking en la crisis de la Covid-19. Profesional de la Información 2202 [Internet]; 29(4), e290411. https://doi.org/10.3145/epi.2020.jul.11

19. Beldarraín-Chaple ER. La información científica confiabley la COVID-19. Revista Cubana de Información en Ciencias de la Salud 2020;31(3).e1609. https://doi.org/10.36512/rcics v31i3. 1609.g911

20.Fachin J, Camelo de Araujo N, Carvalho de Sousa J. Credibilidade de informações em tempos de COVID-19. Rev. Interam.Bibliot. [Internet];43(3), eRf3. Disponible en: https://revistas.udea.edu.co/index.php/RIB/article/view/3426 19/20803574. doi:org/10.17533/udea.rib.v43n3eRf3

21.Radi B, Wisky L. Infodemia: desinformación antes, durante y después de la emergencia sanitaria. Disponible en: https://latfem.org/infodemia-desinformacion-antes-durantey-despues-de-la-emergencia-sanitaria/

22. Torrealba L. Aportes y posibilidades desde el periodismo ante los riesgos que imponen la desinformación y la posverdad. La Mentira en la Censura. Los Fake News en Venezuela, M. Torrealba, L. Hernández \& A. Cañizález (Coordinadores), Primera Edición, Universidad Católica Andrés Bello, Caracas, 2020:34.

23.OPS y OMS. Entender la infodemia y la desinformación en la lucha contra el COVID-19. Disponible en:https://iris.paho. org/bitstream/handle/10665.2/52053/FactsheetInfodemic spa.pdf? sequence $=14 \&$ isAllowed $=y$

24.Larson HJ. Blocking information on Covid-19 can fuel the spread of misinformation. Nature 2020 [Internet];580(7803): 306. https://doi.org/10.1038/d41586-020-00920-w

25.Fabelo-Concepción S. Escenarios COVID-19 y geopolítica de la infodemia. Disponible en: https://saeeg.org/index.php/ tag/ incertidumbre/page/3/

26. Comisión Europea. Lucha contra la desinformación. Disponible en: https://ec.europa.eu/info/live-work-traveleu/health/coronavirus-response/fighting-disinformation_es

27. Aleixandre-Benavent R, Castelló-Cogollos L, ValderramaZurián JC. Información y comunicación durante los primeros meses de Covid-19. Infodemia, desinformación y papel de los profesionales de la información. Profesional de la Información 2020;29(4):1-17. e290408. https://doi.org/10.3145/epi. 2020.jul.08

28.Sánchez-Tarragó N. Desinformación en tiempos de COVID19: ¿Qué podemos hacer para enfrentarla? Revista Cubana de Información en Ciencias de la Salud 2020;31(2), e1584. https://doi:org/10.36512/rcics.v31i2.1584

29.Zagury-Orly I, Schwartzstein RM. Covid-19: A reminder to reason. N Engl J Med 2020;3 83, 3:e12. https://doi: 10.1056/ NEJMp2009405

30.Ghebreyesus TA. Munich Security Conference; 2020. Disponible en: https://www.who.int/dg/speeches//detail/ munich-security-conference

31. Gonçalves-Sá $\mathbf{J}$. In the fight against the new coronavirus outbreak, we must also struggle with human bias. Nature Medicine 2020;26(3): 305-305. https://doi.org/10.1038/ s41591-020-0802-y

32. Aguilar-Hernández I. Infodemia en el curso de la COVID-19. Revista Electrónica Medimay [Internet], 27(2). Disponible en: http://www.medimay.sld.cu/index.php/rcmh/article/view/166 $1 /$ pdf 261

33.Zaracostas J. How to fight an infodemic. Lancet 2020;395(10225):676. doi: 10.1016/S0140-6736(20)30461-X

34.Eysenbach G. Infodemiology and infoveillance: framework for an emerging set of public health informatics methods to analyze search, communication and publication behavior on the Internet. J Med Internet Res 2009;11(1):e11. https://doi: 10.1016/j.amepre.2011.02.006

35.Arroyo Sánchez A, Cabrejo Paredes JE, Cruzado Vallejos MP. Infodemia, la otra pandemia durante la enfermedad por coronavirus 2019. An Fac med 2020;81(2):230-233. https://doi:org/10.15381/anales.v81i2.17793

36. Espín E. Los tratamientos pseudocientíficos en la pandemia de COVID-19: Aplanar la curva de la "infodemia" también salva vidas. Carta al Editor. Disponible en: http://revistabionatura. com/files/2020.05.03.2.pdf. https://doi.10.21931/RB/2020. 05.03 .2

37. Marangoni AA. En tiempos del COVID-19: pandemia e 
infodemia. Editorial, Revista Argentina de Radiología 2020 https://doi: 10.1055/s-0040-1714051

38. Inneraty D, Colomina C. Introducción: desinformación y poder, la crisis de los intermediaries. Revista CIDOB d'Afers Internacio nals 2020;124:7-10.

39. Kim L, Fast S, Markuzon N. Incorporating media data into a model of infectious disease transmission. PLoS ONE 2019 [Internet];14(2), e0197646. https://doi.org/10.1371/journal. pone. 0197646

40. Catalán-Matamoros D. La comunicación sobre la pandemia del COVID-19 en la era digital: manipulación informativa, fake news y redes sociales. Revista Española de Comunicación en Salud, Suplemento 1 2020; S5-S8. https://doi.org/10.20318/ recs.2020.5531

41. Nguyen A, Catalan-Matamoros D. Digital Mis/ Disinformation and Public Engagment with Health and Science Controversies: Fresh Perspectives from Covid-19. Media and Communication 2020;8(2):323. https://doi.org/10.17645/mac. v8i2.3352

42. Bacci S. COVID-19. Una pandemia de desinformación. Med Interna 2020; 36(1):31-34.

43.Zerón A. Pandemia e infodemia. Revista ADM 2020;77(4): 182-184. https://doi.org/10.35366/95110

44. Naeem S Bin, Bhatti R, Khan A. An exploration of how fake news is taking over social media and putting public health at risk. Heal Inf Libr J 2020;hir.12320. https://doi/abs/10.1111/ hir. 12320

45. Gora-Prado S. ¿Presa o conspiranoia? Diario El Comercio, Lima: 2020, agosto 30. Palabras en la Red, Sección El Dominical: p.15.

46. Paredes-Laos J. El peligro del virus de la conspiración. Diario El Comercio, Lima: 2020, setiembre 6. Informe, Sección El Dominical: pp. 4-5.

47. Acosta Y. ¡Qué miedo!. Las Fake News y las emociones. En: La Mentira en la Censura. Los Fake News en Venezuela, M. Torrealba, L. Hernández \& A. Cañizález (Coordinadores), Primera Edición, Universidad Católica Andrés Bello, Caracas, 2020:119.

48. Adams KK, Baker WL, Sobieraj, DM. Myth busters: dietary supplements and COVID-19, Ann Pharmacother 2020;54(8):820-826.

49. Basombrío-Iglesias C. Verdades muy duras y mentiras muy crueles. Diario El Comercio, Lima: 2020, diciembre 16, Sección Opinión: p.26.

50. Bedoya J. Créele a Miguel Bosé y que el Señor te proteja. Diario El Comercio, Lima: 2020, agosto 23, Sección El Dominical, Disculpen la Pequeñez: p.14.

51. Diario El Comercioc. Cuídese de la segunda ola de 'fake news'. Lima: 2020, diciembre 5. Sección Especial: p.13.

52. Diario El Comercio. Los falsos mensajes difundidos por grupos antivacunas. Lima: 2020, diciembre 6. Sección en 4 Pasos: p.12.

53. Diario El Comercio. Teorías conspirativas en la pandemia. Lima: 2020, diciembre 12. Sección Ciencias: p.24.

54. Exitosa. Alcalde de Moche asegura que el dióxido de cloro mejora el vigor sexual. Disponible en: https://exitosanoticias. pe/v1/alcalde-de-moche-asegura-que-el-dioxido-de-cloromejora-el-vigor-sexual/

55. Revista Somos. Fuimos \& Seremos. (2020). Diario El Comercio, Lima: Año XXXIII (1762), p.7.

56. Gaitán-Russo RV. COVID-19: crónica de una infodemia. La segunda pandemia. Revista Española de Comunicación en
Salud 2020 (Suplemento 1); S347-S349. https://doi.org/ 10.20318/recs.2020.5408347-349.

57. Giménez JA, Espinoza JA, Vitale FM, Escalante-Sánchez M, Franceschi MJ, MJ, Cáneva J. Coronavirus y desinformación: la otra pandemia. Disponible en: http://sedici.unlp.edu.ar/bitstream/handle/10915/94170/Docu mento_completo.pdf?sequence $=1 \&$ isAllowed $=y>$

58. Huerta E. La propaganda científica populista. Diario El Comercio, Lima: 2020a, noviembre 1. Sección Ciencias: p.19.

59. Huerta E. ¿Puede una vacuna cambiar nuestro ADN? Diario El Comercio, Lima: 2020b, diciembre 6. Sección Ciencias: p.18.

60. Ioannidis JPA. Coronavirus disease 2019: the harms of exaggerated information and non-evidence-based measures. European Journal of Clinical Investigation 2020[Internet]; 50(4), e13222. https://doi.org/10.1111/eci.13222

61. Kahhat F. Conspiración mundial de la salud. Diario el Comercio, Lima: 2020, setiembre 6. Mundo, Sección El Dominical:p.13.

62. La Tercera. El misterioso laboratorio de Wuhan, sospechoso de iniciar la actual pandemia. Disponible en: https://www.latercera.com/que-pasa/noticia/elmisteriosolaboratorio-de-wuhan-centro-de-unacontroversiamundial/2GYQTFD2DVAQPIJPTNASCGDWV $\mathrm{U} />$

63. Martín-Barato A, López-Doblas M, Luque-Martín N, March-Cerdá JC. Fake news y bulos contra la seguridad y la salud durante la crisis del coronavirus. Escuela Andaluza de Salud Pública. Disponible en: https://bit.ly/2WaX7Ah

64. Organización Mundial de la Salud. Alocución de apertura del Director General de la OMS en la sesión de información para los medios de comunicación sobre el nuevo coronavirus de 2019. Disponible en: https://www.who.int/es/dg/speeches/ detail/director-general-s-remarks-at-the-media-briefing-on2019-novel-coronavirus---8-february-2020

65. Pereyra-Colchado G. Aumenta el rechazo a la futura vacuna. Diario El Comercio, Lima: 2020, diciembre 16. Sección Nacional:p.12.

66. Pidone CL. COVID-19: entre el desconocimiento y la desinformación. Disponible en: http://repositorio.umaza.edu. ar/bitstream/handle/00261/1349/Pidone_COVID$19 \% 20$ Entre $\% 20 \mathrm{el} \% 20$ desconocimiento $\% 20 \mathrm{y} \% 201 \mathrm{a} \% 20 \mathrm{desi}$ nformaci\%c3\%b3n_2020.pdf? sequence $=1 \&$ isAllowed $=y$

67. Reisman A. Vizcarra y sus afirmaciones sobre la vacuna bajo la lupa. Diario El Comercio, Lima: 2020, diciembre 19. Sección Política:p. 6

68. Rosselli D. Covid-19: entre el pánico y la indiferencia. Acta Neurol Colomb 2020;36(2):1-2.

69. Vivas F. Papas, camotes y complots. Diario El Comercio, Lima: 2020, setiembre 6. Informe, Sección El Dominical: p.5.

70. Grimes DR. Correction: On the Viability of Conspiratorial Beliefs. PLoS ONE 2016 [Internet];11(3): e0151003. https://doi.org/10.1371/journal.pone.0151003

71. Diario El Comercio. Las redes sociales también cambian. Lima: 2020, noviembre 7. Ciencias: p.18.

72. Limaye R, Sauer M, Ali J, Bernstein J, Wahl B, Barnhill A, Labrique A. Building trust while influencing online COVID19 content in the social media world. The Lancet Digital Health 2020;2(6):277-278. https://doi.org/10.1016/S2589$7500(20) 30084-4$

73. Hidalgo M, Lira A. Una campaña entre la viralización, memes y 'fake news' Diario El Comercio, Lima: 2020, setiembre 18. Informe: p.6. 
74. Llewellyn S. Covid-19: how to be careful with trust and expertise on social media. BMJ 2020; 368. https://doi:10.1136 /bmj.m1160
75. Diario El Comercio. Una tecnología que sorprende pero que puede ser peligrosa. Lima: 2020. Noviembre 15. Tendencias, Sección El Dominical: p.17.

Contribución de autoría: Gunther Naldo Balarezo López ha participado en la concepción del artículo, la redacción

del manuscrito, la revisión crítica del manuscrito y aprobación de su versión final.

Conflicto de interés: El autor no tiene conflicto de interés con la publicación de este trabajo.

Financiamiento: Autofinanciado.

Citar como: Balarezo-López O. El virus de las "noticias falsas” en la pandemia del COVID-19. Diagnóstico(Lima).

2021;60(1):40-49.

DOI: 10.33734 /diagnostico.v60i1.267

Correspondencia: Gunther Naldo Balarezo López. Correo electrónico:gbalarezo52@gmail.com

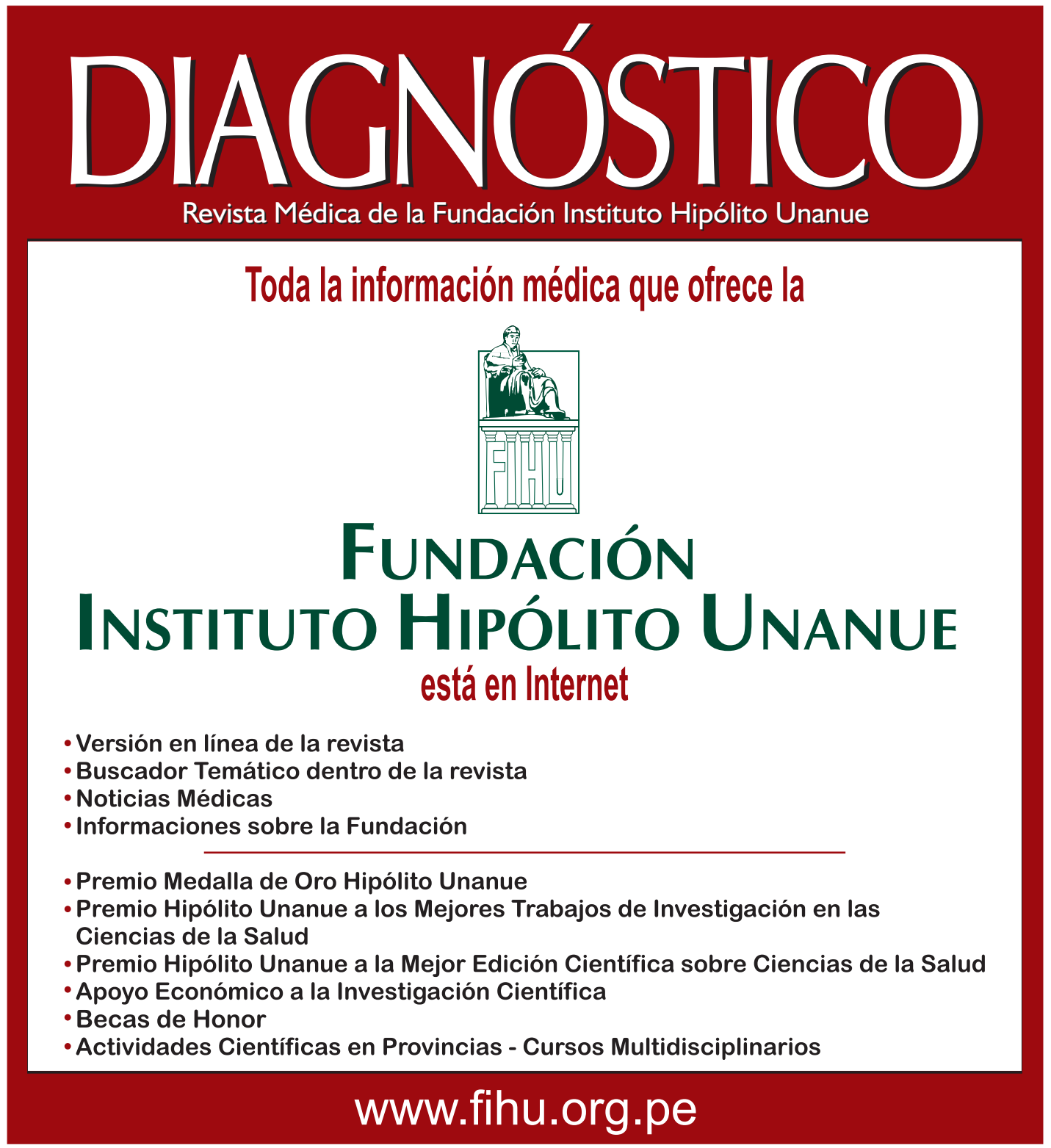

